\title{
Florestas secundárias tropicais: ecologia e importância em paisagens antrópicas
}

\author{
Ima Célia Guimarães Vieira \\ Museu Paraense Emílio Goeldi/MCTI
}

Toby A. Gardner

University of Cambridge

Nesta era geológica em que vivemos, conhecida informalmente como Antropoceno, as atividades humanas têm deixado a sua marca de diversas maneiras nos ecossistemas da Terra. Entre os mais marcantes nas últimas décadas está a transformação de vastas áreas de florestas tropicais, a partir da alteração, degradação ou supressão da vegetação nativa e subsequente regeneração das florestas secundárias em áreas recentemente abandonadas ou em estágios de pousio agrícola.

Antes da chegada dos europeus, uma boa parte do Brasil era dominada por florestas contínuas, muito pouco alteradas por grupos indígenas, que faziam pequenos cultivos e selecionavam frutas e outras essências florestais. A primeira floresta a ser submetida à colonização portuguesa foi a Mata Atlântica, que há apenas 500 anos cobria uma extensão superior a 1,5 milhões de $\mathrm{km}^{2}$ - restam, hoje, menos de $175.000 \mathrm{~km}^{2}$. Por sua vez, as grandes aberturas na Amazônia aconteceram principalmente na última metade do século XIX, quando esta região passou a se constituir em uma fronteira de colonização agrícola, e as áreas de florestas de terra firme do leste do Pará passaram gradativamente a ser exploradas e alteradas. A partir da implantação, na década de 60, de um modelo predatório de desenvolvimento na região, a supressão de florestas nativas para dar lugar a empreendimentos agropecuários levou à completa alteração da paisagem regional e à perda das funções e dos benefícios de grande trecho de florestas - os ecossistemas secundários em expansão passaram a se constituir, então, em uma 'segunda natureza', resultado das modificações realizadas pelo homem.

Espera-se que essas paisagens dominadas por mosaicos de áreas de produção, florestas degradadas e florestas em regeneração forneçam, além de commodities agrícolas e florestais, diversos outros benefícios, entre os quais a proteção da biodiversidade e a manutenção dos mais diversos serviços ambientais: a proteção da integridade ecológica dos sistemas aquáticos; o sequestro e a conservação de estoques de carbono para amenizar as mudanças climáticas; a manutenção dos processos de polinização e o controle de pragas naturais, que dependem criticamente da biodiversidade nativa.

Nessas paisagens, florestas em diversos estágios de degradação e regeneração (a partir da limpeza total de uma área ou dos impactos históricos de extração de madeira e queimadas) têm um papel fundamental. Em muitas paisagens de colonização antiga, as florestas secundárias que crescem nas áreas abandonadas ou não produtivas representam uma proporção significativa da cobertura total de floresta - é o caso da grande maioria da Mata Atlântica, mas também de áreas antigas no leste da Amazônia, como a Zona Bragantina, além de muitas outras áreas antropizadas dos trópicos.

Considerando a vasta extensão das florestas secundárias nos trópicos úmidos e sua predominância em biomas como a Mata Atlântica do Brasil, aponta-se uma demanda urgente para avançar com o entendimento e apreciação dos serviços ambientais que essas florestas fornecem e indicar as lacunas de pesquisa existentes, o que é essencial para a formulação de modelos de restauração e reabilitação florestal. $\bigcirc$ reconhecimento do papel das florestas secundárias na manutenção estrutural e funcional da biodiversidade em nível de paisagem e seu potencial como suporte para o 
desenvolvimento sustentável passa pela intensificação dos estudos sobre a dinâmica dessas florestas e das condições atuais em que elas se encontram em diversas paisagens antropizadas nos trópicos.

Esse dossiê, "Florestas secundárias tropicais: ecologia e importância em paisagens antrópicas", é uma contribuição do Instituto Nacional de Ciência e Tecnologia (INCT) Biodiversidade e Uso da Terra na Amazônia, sediado no Museu Paraense Emílio Goeldi (MPEG), e é integralmente voltado a um ecossistema que requer bastante atenção às florestas secundárias. Ele apresenta, em um momento crítico para as florestas do Brasil devido às mudanças ocorridas no Código Florestal brasileiro, um conjunto de sete artigos e uma nota de pesquisa abordando diversos aspectos relacionados a este tema. Considerado em conjunto, o dossiê traz uma síntese de muitos anos de pesquisa e experiência prática de pesquisadores que trabalham com florestas secundárias em diversos lugares do Brasil e em outros países.

O dossiê é aberto com o excelente artigo "Regeneração de florestas tropicais", de Robin Chazdon, que oferece um panorama sobre o conhecimento ecológico atual a respeito de florestas secundárias, assim identificando as bases críticas para qualquer projeto de conservação e prioridades para futuras pesquisas. Baseada em mais de trinta anos de estudos em florestas secundárias na America Latina, Chazdon discorre sobre as possíveis trajetórias e estágios sucessionais que nelas se desenvolvem e aborda como essas trajetórias dependem do tipo de uso anterior da terra, da proximidade da floresta primária e da disponibilidade de fauna dispersora de sementes. Ela discute também as mudanças na diversidade funcional da vegetação e na composição das espécies de plantas e animais, e os efeitos dessas mudanças na futura trajetória do sistema. Ao final, Chazdon reflete sobre a importância das estratégias de reflorestamento passivo ou ativo e ressalta o papel da restauração ativa com intervenções para superar barreiras específicas à regeneração natural das florestas dentro de um determinado sítio (como erosão do solo, colonização inadequada de espécies por limitação de dispersão e a dominância de ervas daninhas ou espécies invasoras de gramíneas).

No segundo artigo, intitulado "Estratégias para auxiliar na conservação de florestas tropicais secundárias inseridas em paisagens alteradas", Brancallion et al. seguem a abordagem geral dada por Chazdon, com um enfoque maior sobre o estado das florestas secundárias na Mata Atlântica e na floresta amazônica, e os principais fatores que as ameaçam. Além de apontar a importância dos impactos do setor agrícola (incluindo a dependência no uso do fogo e sistemas de corte e queima pelos pequenos produtores) e os relacionados à extração de madeira e produtos não madeireiros, os autores chamam atenção aos muitos efeitos indiretos que podem prejudicar a trajetória sucessional dessas florestas e impedi-las que avancem até o estágio de florestas maduras. Exemplos de tais efeitos indiretos incluem a dominância do dossel por lianas hiperabundantes e árvores pioneiras favorecidas pela perturbação (como espécies de bambus), que podem proliferar e dominar florestas secundárias, substituindo espécies climácicas. Este processo pode levar a uma forte homogeneização e simplificação biótica das florestas secundárias, resultando na perda de espécies endêmicas e de funcionais grupos chave de plantas e animais. Com essa base, Brancallion et al. passam a discutir estratégias para o aumento e conservação de florestas secundárias em paisagens muito (caso do Mata Atlântica) e pouco alteradas (caso da Amazônia), abordando aspectos ecológicos, socioeconômicos e legais. Ao longo desta revisão, eles concluem que é essencial possuir uma visão holística sobre as diferentes causas da destruição e degradação de florestas secundárias, a fim de apresentar soluções que atendam aos aspectos ecológicos, socioeconômicos e legais necessários para sustentar um futuro favorável para as florestas secundárias nos trópicos.

Os próximos cinco trabalhos apresentam estudos de caso, mostrando padrões importantes nas mudanças ecológicas que acontecem ao longo das trajetórias de sucessão secundária. Todos esses artigos têm enfoque no bioma Amazônia, mas, ao mesmo tempo, trazem resultados e inferências pertinentes a outras florestas tropicais menos conhecidas.

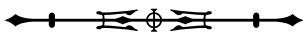


No trabalho "Dinâmica e trajetórias da sucessão secundária na Amazônia central", Massoca et al. apresentam dados muito interessantes do Projeto Pioneiras na Amazônia Central, que mostram uma grande diferença na trajetória da sucessão secundária nas áreas que sofreram um uso intensivo com a utilização de fogo para renovação de pastagens, comparativamente àquelas áreas com um histórico de uso menos intensivo. Nas áreas de uso intensivo, as florestas secundárias estão dominadas pelo gênero Vismia, sendo colonizadas por poucas espécies e permanecem num estágio de sucessão estagnada. Por outro lado, as áreas que não sofreram ciclos de queimada foram dominadas pelo gênero Cecropia e mostram uma composição florística muito mais diversa. Embasado no seu conhecimento da região, os autores apresentam recomendações práticas para melhorar e acelerar o processo de regeneração, notando que as técnicas precisam ser escolhidas dependendo do histórico de uso da área.

Coelho et al. apresentam uma "Caracterização do processo sucessional no Projeto de Assentamento Benfica, sudeste do estado do Pará, Amazônia oriental”, detalhando mudanças na estrutura e composição florística que ocorrem em áreas de floresta secundária com diferentes idades, características fisionômicas e histórico de uso. Ao contrário do esperado, os autores não encontraram grandes diferenças no número de espécies de árvores entre as florestas mais jovens e mais velhas, assim identificando o histórico de uso como um fator tão importante quanto a idade de abandono da área para determinar o processo de sucessão. Eles concluem que a combinação dos parâmetros estruturais e florísticos, considerando o histórico de uso, permitem uma definição mais clara dos estágios sucessionais.

No terceiro estudo de caso, mudamos o olhar para a serapilheira e o ciclo de nutrientes, em que Hayashi et al. discutem a "Vinculação da dinâmica do nitrogênio e do fósforo na produção e decomposição de serapilheira durante a sucessão da floresta secundária na Amazônia oriental". Neste artigo, os autores testam a hipótese de que a mudança do uso da terra (desmatamento-agricultura-abandono agrícola) pode alterar a estequiometria da ciclagem de nutrientes nas florestas secundárias em relação às florestas maduras. Como esperado, a produção e a perda de $N$ durante a decomposição foram baixos nas florestas jovens, mas aumentaram com a idade da floresta. Por sua vez, a ciclagem de $\mathrm{P}$ foi conservadora em todas as idades, sugerindo que a falta de $\mathrm{P}$ pode limitar ou colimitar a produtividade da floresta, juntamente com a variação na disponibilidade de $\mathrm{N}$ na serapilheira.

Salomão et al., no artigo "Sistema Capoeira Classe: uma proposta de sistema de classificação de estágios sucessionais de florestas secundárias para o estado do Pará", usando uma base de dados obtida a partir de 120 inventários do leste do Pará e apoiados na experiência dos autores na região, propõem um sistema prático de realizar a classificação de florestas secundárias. O sistema proposto é adequado para inventários simples e rápidos em áreas sujeitas à expansão da produção agrícola no Pará, e fornece subsídios que permitem ao poder público formular legislações específicas e orientar os procedimentos de licenciamento de áreas para fins de supressão, manejo e conservação da vegetação nativa. De certa forma, o sistema pode também contribuir para a identificação de áreas degradadas, consideradas prioritárias para a implantação de programas de restauração florestal.

Por último, Tabarelli et al. apresentam algumas análises gerais e importantes no artigo "Florestas secundárias como repositórios de biodiversidade em paisagens antrópicas: evidências dos neotrópicos". Baseados na experiência de seus trabalhos nas paisagens altamente modificadas da Mata Atlântica do nordeste do Brasil, Tabarelli et al. observam que os pequenos remanescentes de floresta primária que estão sofrendo um processo de degeneração por meio de efeitos de borda, isolamento e extração de recursos naturais, e as áreas de floresta em regeneração, têm a tendência de convergir do ponto de vista de estrutura e composição taxonômica e funcional. Essas observações enfatizam ainda mais

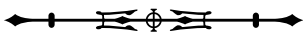


a necessidade urgente de se desenvolver uma perspectiva holística sobre o manejo de paisagens florestais antropizadas que leve em consideração o contexto conceitual, ecológico e espacial.

Ainda no tema de produtividade, mas de um ponto de vista agrícola, Brienza Júnior, em sua nota de pesquisa intitulada "Enriquecimento de florestas secundárias como tecnologia de produção sustentável para a agricultura familiar", identifica que acelerar o acúmulo de biomassa e nutrientes durante o período de pousio por meio do plantio de árvores de crescimento rápido é estratégico para o produtor. Com implicações bastante práticas para as milhares de famílias que dependem do sistema de corte e queima, Brienza Júnior mostra como um plantio de espécies florestais leguminosas permite a redução do tempo de pousio de cinco anos (tradicional) para apenas dois anos em pousio enriquecido.

Como se vê, trata-se de uma amostragem bem representativa da amplitude de estudos sobre as florestas secundárias no Brasil, que nos fornece uma compreensão ampla acerca da ecologia desse ecossistema e de formas de valorizar o seu papel na paisagem regional.

O resultado aqui apresentado, com certeza, incentivará outros ecólogos a se embrenhar por 'juquiras' e 'capoeiras' e estudar essas que, certamente, podem ser consideradas como parte das florestas do futuro.

Com muita satisfação, desejamos boa leitura a todos!

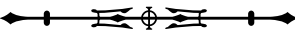

